\title{
$\mathrm{ADHD}$ 치료에서 가족치료캠프의 적용
}

\author{
황병주 ${ }^{1)}$ - 안동현 ${ }^{2)}$. 이재영 ${ }^{3}$ \\ 마더스병원 정신건강의학과, ${ }^{1)}$ 한양대학교 의과대학 정신건강의학교실, ${ }^{2)}$ 청주성모병원 정신건강의학과 ${ }^{3)}$
}

\section{Application of Family Treatment Camp in Treatment of ADHD}

\author{
Byung-Ju Hwang, M.D. ${ }^{1)}$, Dong-Hyun Ahn, M.D., Ph.D. ${ }^{2)}$ and Jae-Young Lee, M.D. ${ }^{3)}$ \\ ${ }^{1)}$ Department of Psychiatry, Motherth Hospital, Ulsan, Korea \\ ${ }^{2)}$ Department of Psychiatry, Hanyang University College of Medicine, Seoul, Korea \\ ${ }^{3)}$ Department of Psychiatry, Cheongju St. Mary's Hospital, Cheongju, Korea
}

Objectives : Demands for comprehensive and intensive treatment programs for treatment of children with attention-deficit hyperactivity disorder (ADHD) who suffer from serious impairment in various psychosocial areas are increasing. The aim of this study was to evaluate the possibility of developing new types of camp programs focused on improving social adjustment of children and helping parents effectively manage their children's problem behaviors.

Methods : Fifteen children diagnosed as ADHD according to Diagnostic and Statistical Manual of Mental Disorders-IV (mean age 9.5 years) and their parents participated in this program. Eight consecutive camps were held at two-week intervals, from Jun 2007 to Oct 2007 in an adolescent training center located at Chungtaesan, in Korea. Each camp program included social skills training in the classroom and outdoor activities in the forest for children, as well as parent training for mothers. In addition, after the sixth camp, we conducted one parental session for fathers and a three-day booster family camp three months later. Finally, eleven families adhered to the program.

Results : All children, parents, and therapists rated questionnaires or checklists at baseline, intra-, and post-treatment. Parenting burden rated using the Parenting Stress Index showed a significant decrease, from 57.89 to 46.22 ( $\mathrm{p}=.019$ ). And, overprotection rated using the Parenting Bonding Instrument showed a significant decrease, from 16.56 to 12.44 ( $p=.046$ ). However, no significant improvement in children's behavioral and emotional problems was observed.

Conclusion : In this study, the consecutive ADHD family camp program was effective for empowerment of parental competency, but not for general improvement of children's behavioral and emotional symptoms.

KEY WORDS : ADHD · Family Camp · Comprehensive Treatment Programs.

\section{서 론}

주의력결핍 과잉행동장애(attention-deficit hyperactivity disorder, $\mathrm{ADHD}$ )는 주의산만과 과잉행동, 충동성을 핵심증 상으로 가지며, 학령기 아동들에게서 3-5\%의 유병률로 가장

접수완료 :2012년 4월 10일 / 심사완료:2012년 5월 8일

Address for correspondence: Dong-Hyun Ahn, M.D., Ph.D., Department of Psychiatry, Hanyang University College of Medicine 222 Wangsimni-ro, Seongdong-gu, Seoul 133-791, Korea

Tel : +82.2-2290-8425, Fax : +82.2-2298-2055

E-mail : ahndh@hanyang.ac.kr

본 연구는 한국녹색문화재단의 연구비 지원에 의하여 수행되었음.

본 연구의 요지는 2008년 5월 17일 대한소아청소년정신의학회 춘계학술대회에서 포스 터로 발표되었음.
흔히 나타나는 행동장애에 속한다.1) 특히, 초기 아동기에 발병 하여 만성 경과를 밟으면서 가정, 학교, 사회 등 여러 기능영역 에 광범위한 지장을 초래하는 매우 중요한 질병이다. 상기 핵심 증상 이외에도 공격적이고 충동적이며 타인과의 상호작용에서 상대방의 자극에 적절하게 반응하지 못하는 사회성의 미숙함 을 동반한다. ${ }^{2}$ 규칙을 지키기 힘들고 비순종적이어서 부모와의 갈등이 잦고, 야단이나 지적, 체벌과 같은 부정적인 피드백을 지 속적으로 받음으로 인해 자존감이 저하되고 위축되어 우울과 같은 정서적 어려움을 가지기 쉽다. ${ }^{3)}$ 그리고, 다양한 부정적 경 험이 품행장애와 약물남용 등 청소년 비행이나 성인기 반사회 적 행동으로 이어지기도 한다."

상기한 개인적, 사회적 문제를 줄이기 위해 효과적인 아동기 의 개입이 요구됨에도 불구하고 아직까지 $\mathrm{ADHD}$ 에 대한 단일 
한 효과적 치료법은 발견되지 않고 있다. 현재 시행되고 있는 $\mathrm{ADHD}$ 의 치료법 중 가장 일반적이고 효과적인 것은 약물치료 로서 주의력과 충동조절능력을 향상시키고, ${ }^{5)}$ 과다활동과 공격 성을 감소시키는 등 $\mathrm{ADHD}$ 의 핵심증상들을 현저히 개선시키 는 효과가 있다. ${ }^{6}$ 행동치료는 부모를 매개자로 삼아 아동의 긍 정적 행동을 강화하고 부정적 행동을 줄이는 방식으로 이루어 지는데, 이러한 부모훈련은 아동의 비순종 행동을 줄이고 모자 간의 긍정적인 상호작용을 촉진하는 효과가 있다.) 사회기술 훈련은 또래관계에서 지켜야 할 규칙을 교육하고, 다양한 갈등 상황에서 적절하게 대처하는 사회적 기술을 가르치는 것으로, $\mathrm{ADHD}$ 아동의 부정적인 또래관계를 개선하고 친사회적인 행 동을 증가시키기 위해 필요하다. ${ }^{8)}$

한편, 약물치료 단독으로는 $\mathrm{ADHD}$ 아동의 자아개념과 사회 적 적응, 부모와의 갈등을 실질적으로 개선시켜 주지는 못하며, ${ }^{9}$ 부모교육이나 사회기술훈련 또한 부주의나 활동과다, 충동성 등의 근본적 문제를 해결하지 못하므로 ${ }^{10}$ 병합치료의 필요성이 제기된다. 병합치료의 우수성을 살펴보기 위한 연구로는 Pelham 드ㅇㅣㅣ 이 ADHD 아동에 대하여 약물 단독치료와 행동치료 적 중재의 병합치료를 실시한 연구 19 가지를 고찰한 결과 그 중 13 가지 연구에서 병합치료가 약물치료나 행동치료 단독에 비해 우수한 효과가 있었다고 보고하였다. 국내에서도 Hong 등'2)과 $\operatorname{Kim}$ 등 $^{13)}$ 이 약물치료 단독에 비해 부모훈련 병합치료가 더욱 효과적이었다는 연구 결과를 보고한 바 있다. 보다 통합적인 치료프로그램의 예로는 미국 뉴욕대학의 Pelham과 Hoza ${ }^{14)}$ 가 1980년부터 시행하고 있는 summer treatment program이 있 는데, 여름방학을 이용해 주 5일, 8주간 진행되는 집중적인 프 로그램이다. 사회기술훈련, 체육활동, 협동과제 등으로 진행되 고, 점수보상체계를 적용하여 행동수정을 돕고, 매일 부모교 육을 시행한 결과, 외래치료만 시행했을 때보다 부모와 교사의 치료 만족도가 높았다고 보고하였다.

따라서, $\mathrm{ADHD}$ 는 약물치료와 부모교육, 사회기술훈련이 병 행되었을 때 각각의 단독치료에 비해 우수한 치료효과를 기대 할 수 있다. 현재, 병원환경에서 이루어지는 위의 치료들은 제 한된 시간 동안만 아동을 관찰할 수가 있으므로 아동이 가지 는 다양한 강점과 단점을 충분히 파악하기 어렵다. 또, 부모훈 련과 사회기술훈련에서 한시간 동안 배운 것을 현장에서 직접 적용하고 치료자에게 피드백을 받을 수 있는 여건이 되지 못 한다. 따라서, 이들 아동과 부모들이 충분한 시간 동안 치료에 전념할 수 있고 치료자와 상호작용하며 긍정적인 피드백을 받 을 수 있는 집중적인 치료환경을 필요로 한다. 이러한 필요성 을 충족시키기 위해 캠프라는 형태의 적용을 고려할 수 있다. 본 연구에서는 캠프의 장소를 숲으로 정하였는데, 대상자들이 도시에서 벗어나는 색다른 경험을 할 수가 있고, 이를 통해 부
모가 아동에게 집중적인 관심을 쏟을 수가 있으므로 평소 부 정적인 평가에 익숙해져 있는 아동들에게 긍정적인 자기개념형 성에 도움이 될 것으로 기대하였다. 또한, 숲에서 이루어지는 다양한 체험활동을 통해 힘든 것을 이겨내는 성취경험을 할 수 있고, 치료자, 부모, 또래와의 대인관계기술을 늘려 가는 계기 가 될 것으로 기대하였다. 본 연구에서는 숲이라는 환경적 자 극과 숲에서의 적절한 활동 및 체험집단간의 교류가 부정적 대 인관계 개선, 친사회적 행동의 증가, 부모의 양육행동 개선과 같은 실질적 치료효과를 가져오는지 검증하고, 이를 토대로 $\mathrm{ADHD}$ 아동의 정서 및 행동문제 개선을 위한 새로운 치료프 로그램의 개발 가능성을 검토하고자 하였다.

\section{방 법}

\section{1. 승인 및 기간}

본 연구는 한양대학교병원 소아정신과 임상시험위원회(IRB) 의 서면 심의 검토 후 승인 하에 2007년 6월 1일부터 2008년 1월 31일까지 시행하였다.

\section{2. 대 상}

한양대학교병원 소아정신과 및 경기도 소재 소아정신과의 원에 내원하여 심리학적 평가와 소아정신과 전문의의 소견에 따라 미국정신의학회 정신질환진단편람 제4판 ${ }^{1}$ 에 근거하여 $\mathrm{ADHD}$ 로 진단된 아동 15 명과 그 어머니 및 아버지를 대상 으로 하였다. 아동의 평균연령은 9.50세이고 범위는 8.3010.40 세까지였으며 대상아동은 모두 남아이고, 평균지능은 112.00 이다.

\section{3. 절 차}

\section{1) 치료의 장소}

강원도 횡성군 청태산에 위치한 청소년 수련시설 '숲체원'에 서 이루어졌고, 일부는 한양대학교병원에서 수행되었다.

\section{2) 1차 캠프}

총 8회에 걸친 각 1 박 2 일의 캠프로 이루어졌다. 2007년6월 23 일에 1회를 시작하여 2주 간격으로 매월 2, 4째 주 토, 일요 일에 캠프를 시행하였다.

\section{3) 아버지 모임}

6회 캠프가 끝난 다음인 2007년 9월 14일에 한양대학교병 원에서 실시하였고, 9 가족의 부모님(총 18명)이 참여하였다. 치 료캠프의 취지와 목적, 진행상황에 대해 설명하여 아버지들 
의 질병에 대한 이해도 및 아동에 대한 관심을 향상시키기 위한 목적으로 개최하였다.

\section{4) 2 차 캠프(심화 캠프)}

2008년 1월 25일부터 1월 27일까지 2박 3일 동안 같은 장소에 서 시행하였고, 1 차 때와는 달리 어머니뿐만 아니라 아동의 아버 지와 형제도 참여하는 가족캠프로 진행하였다.

\section{5) 치료의 구성}

8 회에 걸친 1 차 캠프는 한국녹색문화재단이 제공하는 숲 체험 프로그램과 한양대학교병원 연구진이 제공하는 아동의 사회기술훈련 프로그램 및 부모훈련 프로그램으로 구성되었 다. 아동의 사회기술훈련과 부모훈련 프로그램은 동일한 시간 에 아동그룹과 부모그룹으로 나누어 각각 진행하였고, 숲 체 험 프로그램의 내용은 사회기술훈련의 주제와 연관성을 가지 도록 고안하여 아동이 사회기술훈련에서 배운 것을 숲 체험 활동에서 실제 적용할 수 있도록 하였다. 2차(심화) 캠프는 숲 체험 프로그램과 함께 아버지, 어머니가 모두 참여하는 부모교 육 및 아동의 학습동기증진 프로그램으로 구성되었다. 1, 2차 캠 프의 숲 체험 활동 및 사회심리적 치료 프로그램의 진행 순서 및 각 회기별 주제의 요약은 Table 1 과 같다.

\section{(1) 부모훈련}

Massachusetts 의과대학의 Barkley가 고안한 부모훈련 프 로그램을 $\mathrm{Ahn}$ 과 $\mathrm{Kim}^{15}$ 이 수정, 보완한 프로그램을 사용하였 다. 부모훈련은 한양대병원 소아정신과 전임의가 주진행을 맡 아 양육 및 훈육방법 등의 강의를 맡고 어머니들과의 자유토
론을 진행하였다. 보조진행을 맡은 임상심리사 1 인은 이전 회 기에 내준 과제물을 점검하고, 토론 내용 중 빠진 부분이 있으 면 보충하는 역할을 하였다.

\section{(2) 사회기술훈련}

Piffner와 McBurnett이 개발한 사회기술훈련 프로그램을 $\mathrm{Ahn}$ 등히이 수정, 보완한 프로그램을 사용하였다. 주진행을 맡 은 아동학과 대학원생이 전체 진행 및 점수평가를 하였고, 3-4 개 조를 담당하는 보조치료자(한양대병원 전임의와 임상심리 사 각 1 인)가 아동들의 과제를 돕거나 이탈하는 아동들을 통제 하는 역할을 하도록 했다.

\section{(3) 숲 체험 프로그램}

3 조 내지 4 조로 나누어 1 명의 숲 해설가가 각 조의 아동들 을 인솔하여 프로그램을 진행하였다

\section{4. 평가도구}

치료 시작 전, 4회 캠프 종료 후, 그리고 치료종결(8회 캠프) 직후로 나누어 3차례에 걸친 설문지 조사를 하였다. 설문지는 아동용과 부모용으로 나누어 각각 평가하게 하였다.

\section{1) 아동용 설문지}

(1) 소아우울 척도(Child Depression Inventory, CDI)

$\operatorname{Kovacs}^{17)}$ 의 소아우울척도를 Cho와 Lee 등 ${ }^{18}$ 가 번안하고 표준화한 ‘한국형 소아우울척도’이다. 총 27문항으로 구성되 어 있으며, 각 문항에 제시되어 있는 3 문항의 서술문 중 지난

Table 1. Details of the schedules and contents of the program

\begin{tabular}{|c|c|c|c|c|c|}
\hline & Sessions & Time & Parent training & Social skills training & Outdoor activities \\
\hline \multirow[t]{8}{*}{ Regular camps } & 1 & 2007.6 .23 & Why children misbehave? & $\begin{array}{l}\text { Introduction of the } \\
\text { programs }\end{array}$ & $\begin{array}{l}\text { We are different, } \\
\text { but important. }\end{array}$ \\
\hline & 2 & 2007.7. 14 & Pay attention! & Becoming a good friend & We are all friends \\
\hline & 3 & 2007. 7. 28 & $\begin{array}{l}\text { Increasing compliance and } \\
\text { independent play }\end{array}$ & Accepting results & That's OK \\
\hline & 4 & 2007.8. 11 & $\begin{array}{l}\text { When praise is not enough : } \\
\text { Poker chips and points ( } 1 \text { ) }\end{array}$ & Talking with friend & $\begin{array}{l}\text { I'm interested in you, } \\
\text { how about you? }\end{array}$ \\
\hline & 5 & 2007. 8. 25 & $\begin{array}{l}\text { When praise is not enough : } \\
\text { Poker chips and points (2) }\end{array}$ & Decreasing impulsivity & It's my opinion \\
\hline & 6 & 2007.9 .8 & $\begin{array}{l}\text { Time-outs and other } \\
\text { disciplinary methods }\end{array}$ & $\begin{array}{l}\text { Managing conflict } \\
\text { with friend }\end{array}$ & How about this solution? \\
\hline & 7 & 2007.10 .13 & $\begin{array}{l}\text { Problem solving } \\
\text { communication training }\end{array}$ & Problem solving & I understand you \\
\hline & 8 & 2007. 10. 27 & Communication skills & Managing rage & Manage your anger \\
\hline \multirow[t]{2}{*}{ Booster camps } & 9 & 2008. 1. 25-27 & $\begin{array}{l}\text { Watching video about } \\
\text { ADHD and discussion }\end{array}$ & $\begin{array}{l}\text { Learning motivation } \\
\text { improvement program (1) }\end{array}$ & Learn from nature \\
\hline & 10 & & $\begin{array}{l}\text { Lecture and discussion } \\
\text { about ADHD }\end{array}$ & $\begin{array}{l}\text { Learning motivation } \\
\text { improvement program (2) }\end{array}$ & \\
\hline
\end{tabular}


2주 동안 자신의 느낌과 생각을 가장 잘 나타내는 서술문을 고르도록 되어 있다.

(2) 상태불안 및 특성불안 척도(State-Trait Anxiety Inventory for Children, STAIC)

Spielberger ${ }^{19}$ 에 의해 개발된 척도로서 $\mathrm{Cho}$ 와 $\mathrm{Choi}^{20}$ 에 의 하여 신뢰도 및 타당도 검증이 이루어진 바 있다. 각각 20개 의 항목으로 이루어져 있고, 각 항목에 대해 1-3점으로 채점 된다.

(3) 자아존중감 척도(Self-Esteem Scale)

Coopersmith $^{21}$ 와 Pope 등 ${ }^{22}$ 의 연구를 참조하여 Choi와 $\mathrm{Jeon}^{23)}$ 이 우리나라 아동의 자아존중감 측정도구로 개발하였 다. 총 32문항이며 5점 리커트 척도로 구성되어 있다.

(4) 이슈 체크리스트(Issue Checklist)

Arthur와 Sharon ${ }^{24)}$ 이 청소년을 대상으로 그들의 부모들 과의 사이에서 느끼는 갈등상황의 종류와 갈등의 심한 정도 를 평가하기 위해 개발한 것을 번역하여 사용하였다. 원래 44문항인데, 아동의 연령상 부적절한 7문항(성, 흡연, 아르바 이트 등)을 제외한 37문항으로 질문지를 구성하였다. 37 개의 주제들 중 지난 2주 동안 부모와 이야기해 본 적이 있는 것 을 선택하게 하고, 그 주제에 한하여 대화가 얼마나 격렬했는 지의 정도를 1-5점 사이에서 선택하게 되어 있다.

(5) 부모-자녀 결합형태검사(Parental Bonding Instrument, $\mathrm{PBI}$ )

Parker 등 ${ }^{25}$ 이 개발하고 Song ${ }^{26)}$ 이 신뢰도 및 타당도 검증 을 한 것으로서, 부모와 자녀간의 관계에 작용하는 부모역할 을 측정하기 위한 도구이다. 어머니가 아동에게 어떻게 대하 는지에 대해 아동이 평가하도록 하였다. 부모의 돌봄과 과보 호 두 가지 요인을 평가하며 각 문항은 0-3점으로 채점된다.

\section{2) 부모용 설문지}

(1) 아동행동조사표(Child Behavior Checklist, CBCL) 아동의 사회적 적응 및 정서, 행동문제를 평가하기 위해 Achenbach와 Edelbrock ${ }^{27}$ 이 제작한 것을 $\mathrm{Oh}$ 등 $^{28}$ 이 번역하 여 표준화한 도구이다. 전체 113 개의 각 문항마다 아동의 행동 문제를 0-2점으로 평정한다. 위축, 신체증상, 우울/불안, 사회 적 문제, 사고의 문제, 주의집중 문제, 비행, 공격성의 8 개 문 제행동 척도와 내현적 문제 척도(위축, 신체증상), 외현적 문 제척도(비행, 공격성), 성 문제를 다루는 특수 척도(4-11세), 총
문제행동 점수 척도의 모두 12 개 문제행동 척도들로 이루어 져 있다.

(2) 파탄적행동 평가 척도(Disruptive Behavior Disorder Rating Scale, DBDRS)

주의력결핍, 과잉행동, 반항행동을 묻는 총 26 문항으로 구성 되며 그 심한 정도에 따라 0-3점으로 채점하도록 되어 있다. ${ }^{29}$

(3) 가정상황질문지(Home Situation Questionnaire, HSQ)

가정과 공공장소의 여러 가지 다양한 상황에서 아동이 나타 내는 과다활동성과 주의집중 정도를 부모가 평가하는 것으로 Barkley ${ }^{29}$ 가 제작하고 $\mathrm{Kim}$ 등 ${ }^{30}$ 이 번안한 것을 사용하였다.

(4) 사회적기술 평정 척도(Social Skills Rating System, SSRS)

Gresham과 Elliott ${ }^{31)}$ 이 개발한 도구로, 아동의 사회적 행동 을 평정하기 위한 것이다. 본 연구에서는 Han 등 ${ }^{32}$ 이 타당화 연구를 실시하여 수렴한 38 개의 문항을 사용하였다.

(5) 양육스트레스 목록표(Parenting Stress Index, PSI)

$\mathrm{Abidin}^{33)}$ 이 제작하고 $\mathrm{Kim}$ 등 ${ }^{34}$ 이 번안한 30문항짜리 척도 로, 부모훈련 후의 스트레스 수준 감소를 적절히 평가해 줄 수 있는 매우 민감한 척도로 알려져 있다.

(6) 이슈 체크리스트(Issue Checklist)

아동용 설문지에서 기술한 것과 동일한 설문지로, 부모가 평가하게 하였다.

(7) 부모-자녀 결합형태검사(PBI)

아동용 설문지에서 기술한 내용의 질문지내용을 그대로 이 용하되, 부모 자신이 자녀에게 어떻게 대하는지를 평가하도록 각 문항의 문장을 변형하여 사용하였다.

\section{5. 자료분석방법}

캠프에 끝까지 참여한 11 가족 중 설문조사에 성실히 응하 여 분석이 가능한 10 가족에 대하여 통계분석을 실시하였다. 치료캠프 전후 아동의 문제행동변화를 알아보기 위해 paired t-test로 비교분석하였다. 아동의 우울, 불안, 자아존 중감과 부모의 양육스트레스, 그리고 부모-자녀 결합형태에 관해서는 캠프시작 전과 4회 캠프 후, 그리고 8회 캠프 종료 후의 결과를 반복측정 변량분석을 통해 분석하였다. 2차(심 화) 캠프 후에는 설문평가가 이루어지지 않아 통계분석대상 에 해당하지 않았다. 통계분석에는 SPSS 11.0 Windows 프 로그램을 사용하였다. 


\section{결 과}

\section{1. 아동의 자기보고에 의한 행동, 정서 변화}

치료 프로그램의 진행에 따른 아동의 정서적 특성 변화를 살펴보기 위해 치료 전, 4회기 후, 8회기 후의 설문조사 결과 를 반복측정 변량분석으로 비교분석하였다. 소아우울 척도, 상태 및 특성불안 척도에서 치료 후 수치상의 점진적 호전이 있었지만 통계적으로 의미 있는 수준이 아니었고, 자아존중 감 척도에서도 치료에 따른 의미 있는 호전이 나타나지 않았 다(Table 2).

\section{2. 부모가 평가한 자녀의 행동, 정서, 사회성 변화}

사회적기술 평정 척도SSRS를 통해 평가한 아동의 사회기술

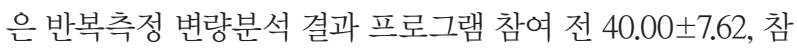
여 중 45.22 \pm 6.34 , 참여 후 46.00 \pm 5.27 로, 점진적 호전의 경과는 관찰되었지만, 통계적 유의성은 없었다(Table 3). 파탄적 행동 장애 평정척도(DBDRS)를 사용하여 프로그램 참여 전후 아동 들의 문제행동의 변화를 상관된 표본 $\mathrm{t}$-검증으로 살펴본 결과, 통계적으로 의미 있는 차이는 없었다. 그리고, 아동행동조사 표(CBCL)를 사용하여 참여 전·후의 내재화 문제, 외현화문 제, 총문제행동 점수를 비교한 결과에서도 의미 있는 변화가 나 타나지 않았다(Table 4). 가정상황 질문지(HSQ)를 통해 아동 이 부모의 지시나 규칙을 따르는 데 있어 문제가 발생하는 가정

Table 2. Comparison of variables between baseline, in-treatment, and post-treatment rated by child

\begin{tabular}{|c|c|c|c|c|c|}
\hline & $\begin{array}{c}\text { Baseline }(N=10) \\
M(S D)\end{array}$ & $\begin{array}{c}\text { In treatment }(N=10) \\
M(S D)\end{array}$ & $\begin{array}{c}\text { Post-treatment }(\mathrm{N}=10) \\
M(\mathrm{SD})\end{array}$ & $\mathrm{F}$ & p-value \\
\hline CDI & $20.22(11.30)$ & $14.00(4.15)$ & $13.56(3.94)$ & 3.23 & .066 \\
\hline State anxiety & $7.86(4.41)$ & $3.71(2.50)$ & $4.00(3.08)$ & 3.00 & .088 \\
\hline Trait anxiety & $18.88(11.54)$ & $11.38(8.50)$ & $12.50(7.95)$ & 2.39 & .128 \\
\hline Self esteem & $94.33(28.36)$ & $106.22(22.50)$ & $100.78(11.46)$ & .99 & .393 \\
\hline PBI (care) & $29.50(8.78)$ & $29.17(8.09)$ & $29.67(5.13)$ & .01 & .987 \\
\hline PBI (overprotection) & $14.71(4.89)$ & $12.00(5.60)$ & $11.29(5.02)$ & 3.43 & .066 \\
\hline $\begin{array}{l}\text { Issue checklist } \\
\text { (number of issue) }\end{array}$ & $17.40(6.04)$ & $19.60(1.26)$ & $13.56(7.27)$ & .17 & .844 \\
\hline $\begin{array}{l}\text { Issue checklist } \\
\text { (intensity of conversation) }\end{array}$ & $30.00(15.26)$ & $37.14(18.26)$ & $26.71(18.07)$ & .89 & .436 \\
\hline
\end{tabular}

CDI : Child Depression Inventory, PBI : Parental Bonding Instrument, SD : standard deviation

Table 3. Comparison of variables between baseline, in-treatment, and post-treatment rated by mother

\begin{tabular}{|c|c|c|c|c|c|}
\hline & $\begin{array}{c}\text { Baseline }(\mathrm{N}=10) \\
M(\mathrm{SD})\end{array}$ & $\begin{array}{c}\text { In treatment }(N=10) \\
M(S D)\end{array}$ & $\begin{array}{c}\text { Post-treatment }(\mathrm{N}=10) \\
M(\mathrm{SD})\end{array}$ & $\mathrm{F}$ & p-value \\
\hline SSRS & $40.00(7.62)$ & $45.22(6.34)$ & $46.00(5.27)$ & 3.35 & .061 \\
\hline Parenting stress & $57.89(10.61)$ & $52.67(9.66)$ & $46.22(13.97)$ & 5.12 & .019 \\
\hline PBI (care) & $21.44(3.47)$ & $23.11(4.08)$ & $24.44(4.19)$ & 1.66 & .221 \\
\hline PBI (overprotection) & $16.56(2.06)$ & $14.56(4.85)$ & $12.44(3.54)$ & 3.74 & .046 \\
\hline $\begin{array}{l}\text { Issue checklist } \\
\text { (number of issue) }\end{array}$ & $23.20(6.55)$ & $18.00(5.66)$ & $21.33(7.35)$ & 1.43 & .265 \\
\hline $\begin{array}{l}\text { Issue checklist } \\
\text { (intensity of conversation) }\end{array}$ & $48.67(17.26)$ & $36.89(18.56)$ & $41.67(13.15)$ & 3.25 & .066 \\
\hline
\end{tabular}

SSRS : Social Skills Rating System, PBI : Parental Bonding Instrument, SD : standard deviation

Table 4. Comparison of variables between baseline and post-treatment child behavior rated by mother

\begin{tabular}{|c|c|c|c|c|}
\hline & $\begin{array}{c}\text { Baseline }(\mathrm{N}=10) \\
M(\mathrm{SD})\end{array}$ & $\begin{array}{c}\text { Post-treatment }(\mathrm{N}=10) \\
M(\mathrm{SD})\end{array}$ & t-value & p-value \\
\hline DBDRS & $30.25(3.20)$ & $27.75(9.44)$ & .79 & .456 \\
\hline CBCL (internalizing problem) & $62.00(8.27)$ & $57.30(6.62)$ & 2.10 & .065 \\
\hline CBCL (externalizing problem) & $57.50(10.34)$ & $55.50(4.67)$ & .70 & .502 \\
\hline CBCL (total problem) & $62.30(8.97)$ & $58.20(6.07)$ & 1.70 & .123 \\
\hline HSQ (number of problem settings) & $10.83(4.27)$ & $10.83(5.46)$ & .00 & 1.00 \\
\hline HSQ (mean severity) & $31.00(16.52)$ & $36.17(24.50)$ & -.65 & .546 \\
\hline
\end{tabular}

DBDRS : Disruptive Behavior Disorder Rating scale, CBCL : Child Behavior Checklist, HSQ : Home Situation Questionnaire, SD : standard deviation 
내 상황 및 문제가 되는 수준을 상관된 표본 $\mathrm{t}$-검증을 통해 살펴 본 결과, 문제 상황의 개수와 강도 면에서 의미 있는 차이 가 관찰되지 않았다(Table 4).

\section{3. 어머니의 양육 스트레스 수준 변화}

프로그램의 진행에 따른 어머니의 양육스트레스의 감소가 있 는지 알아보기 위해 반복측정 변량분석으로 살펴본 결과 참여 전 $57.89 \pm 10.61$, 참여 중 $52.67 \pm 9.66$, 참여 후 $46.22 \pm 13.97$ 로 감소하여 통계적으로 의미있는 변화가 있는 것으로 분석되었 다 $(\mathrm{F}=5.12, \mathrm{p}=.019)$ (Table 3).

\section{4. 부모 자녀 관계 변화}

1) 아동과 어머니가 각각 지각하는 양육태도의 변화가 있는 지 살펴보기 위해 프로그램 전, 중, 후의 부모-자녀 결합형태 검사(PBI) 결과를 반복측정 변량분석하였다. 이 중, 어머니가 지각한 양육태도-과보호 항목에서 참여전 $16.56 \pm 2.06$, 참여 중 $14.56 \pm 4.85$, 참여 후 $12.44 \pm 3.54$ 로 통계적으로 의미있는 수준 의 감소가 있었다 $(\mathrm{F}=3.74, \mathrm{p}=.046)$ (Table 3). 아동이 지각한 양 육태도-과보호 결과는 통계적으로 유의미한 수준은 아니나 유 사한 경향성을 나타내었다(Table 2).

2) 이슈 체크리스트를 사용하여 부모-자녀 간 갈등을 유발 하는 대화 주제의 개수 변화를 알아보기 위해 프로그램 참여 전, 중, 후의 결과를 반복측정 변량분석을 통해 살펴본 결과 아 동 및 어머니가 지각한 대화 개수의 변화와 대화강도 변화에서 통계적으로 의미 있는 호전이 나타나지 않았다(Table 2, 3).

\section{고 찰}

본 연구에서는 ADHD 아동에 대한 통합적 치료형태로서의 캠프의 효과를 검증하기 위해 사전 사후 설문지를 이용한 객관 적 변화를 평가하였고, 부모와 치료자들이 아동의 행동을 가 정과 캠프 현장에서 관찰하는 주관적인 평가를 동시에 진행하 여 다음과 같은 결론과 논의점들을 얻을 수 있었다.

먼저, 어머니의 양육스트레스 및 과보호 감소가 통계적으로 확인되었고 이는 본 캠프의 가장 두드러진 효과로 여겨진다. 양 육스트레스 감소의 원인으로는 다음을 고려해 볼 수 있다. 캠 프 중 이루어진 부모교육을 통해 아동이 가진 $\mathrm{ADHD}$ 라는 질 병에 대한 부모의 이해가 늘어남에 따라, 아동의 행동에 대한 비현실적인 기대가 줄고 아동의 입장에서 이해하려는 노력이 늘었음을 부모들 스스로 보고하였다. 부모훈련을 통해 배운 관심 쏟기와 효과적인 지시방법, 훈육방법 및 보상제도의 적 용을 통해 아동과의 상호관계의 질이 향상되고, 문제행동을 다루는데 있어 부모의 부담이 줄어듦도 보고하였다. 6 회 캠프
를 마친 후 실시한 아버지 모임 이후에, 아동을 양육하는 데 있 어 아버지의 협조도가 향상되었다는 어머니들의 보고가 많았 다. 이는 아동들이 지각한 부모-자녀 결합형태검사(PBI)에서 도 통계적인 유의미성을 가지지는 못했지만 유사한 경향성을 나타내는 것으로 보아, 가정 내에서 부모-자녀 관계에서 양육 의 변화가 두드러지게 호전됨을 보여주었다고 할 수 있다.

반면, 아동의 문제 행동과 정서적 문제는 치료 전후에 통계적 으로 의미 있는 변화가 없었다. $\mathrm{ADHD}$ 의 핵심증상 중 하나인 충동성과 공격성을 가진 아동들은 자극이 주어질 때 여전히 그 런 특성으로 반응한다는 보고가 많았고, 실제 캠프 내에서도 여전히 다툼이나 공격성이 자주 관찰되었다. 설문결과 과잉행 동 및 주의산만, 충동성, 품행문제 등의 여러 문제행동들은 다 소 감소하였으나, 이는 통계적으로 유의한 수준의 변화라고 볼 수는 없었다. 또, 가정 내 상황에서 아동이 지시나 명령, 규칙을 잘 따르지 않는 문제 자체를 감소시키는데도 한계가 있었던 것 으로 보인다. 우울감과 상태불안 역시 수치상 다소 호전되었지 만, 통계적으로 의미 있는 수준에 이르지 못했다. 이러한 결과가 나타난 것은 부주의나 과잉행동, 충동성과 같은 $\mathrm{ADHD}$ 의 핵 심증상들은 일차적으로 약물치료의 대상이며 사회심리적 치료 에 직접적 반응을 기대하기는 어려운 증상들이기 때문으로 보 인다. 따라서, 가족캠프를 통해 아동의 행동문제와 부모의 양 육 고충을 동시에 경감시키고자 기대했던 당초의 연구 목적 중 일부 효과만을 검증하였다. 다만, 통계적 방법을 통한 양적인 변화에 관한 평가와는 별도로, 환자나 치료자에게도 생소한 새로운 형태의 치료캠프를 국내에서 최초로 시도하면서, 아동 행동과 부모 양육태도 변화의 인상적인 부분, 치료자가 바라본 캠프의 긍정적 측면을 열거해본다면 다음과 같다. 첫째, 복잡 하고 다양한 규칙준수와 집중력이 요구되는 도시, 학교, 가정 이라는 환경을 벗어나 숲이라는 자유스러운 공간에서 생활함 으로써 아동의 공격성과 충동성이 건전하게 발산되는 모습을 관찰할 수 있었다. 아동들은 처음 보는 자연현상에 기대 이상 의 집중력을 보이기도 했고, 나뭇가지와 돌 등 자연물을 가지고 상상력을 표현하거나 협동작품을 만드는 과정에서 아동이 자 신의 숨은 재능과 장점을 스스로 발견하면서 자신감을 가지는 모습을 관찰할 수 있었다. 둘째, 평소 부모나 교사로부터 부정 적인 평가에 익숙한 아동들이 질병의 특성을 미리 이해하고 인 정하는 치료자들과 함께 지냄으로써 긍정적인 피드백이 풍부 한 환경을 조성하여 아동들의 자존감 향상에 도움 될 수 있었 을 것으로 생각된다. 또래들로부터 소외되는 경험이 많은 아동 들이 캠프에 와서 친구들을 자유롭게 만나고 상호작용할 수 있 는 기회를 가졌다는 점 역시 부정적 정서와 긴장감을 완화하는 데 도움이 되었을 것으로 짐작된다. 또, 1 차 양육자로서 양육 스트레스가 높은 어머니들이 장시간 함께 생활함으로써 서로 
공감받는다는 느낌을 보고하였고, 질병이나 치료에 관한 정보 공유와 같은 긍정적인 교류가 활발하였다. 치료자로서도 새로 운 치료적 관점을 경험하였는데, 전통적인 외래치료에서는 아 동이 실제 생활에서 나타내는 행동의 문제, 또래관계 문제, 부 모와의 갈등을 직접 관찰하기 어려운 반면, 본 프로그램에서는 이런 사항들을 치료자가 직접 관찰하므로 각 아동의 문제영역 뿐만 아니라 부모의 양육태도의 문제점들에 대한 구체적인 파 악이 가능했고, 따라서 보다 현실적이고 직접적인 행동 중재를 할 수 있었다. 셋째, 치료에서 아버지들만을 대상으로 하는 회 기를 시도하고, 이후 가족캠프회기를 추가하여 부모는 물론 가 족전체가 $\mathrm{ADHD}$ 환아의 치료에 참여하는 계기를 마련한 것은 의미가 크다고 할 수 있다. 또한 이렇게 장시간 아동 및 어머니, 그리고 아버지와 다른 형제들이 참여하면서 캠프를 진행하여 그룹응집력이 높아지고 상당한 유대관계가 형성되어 이들 간의 자발적 모임이 이어지는 자조그룹을 이루게 되었다. 이것은 매 우 의미 있는 성과라고 할 수 있다.

위와 같은 논의점들에 덧붙여 본 연구의 제한점들을 살펴보 면 다음과 같다. 첫째, 대상자 선정과정의 문제로, $\mathrm{ADHD}$ 진단 코드만 적용하여 무작위 명단 추출을 하여 공존질환을 통제 하지 못한 결과, 상당히 다른 특성을 가진 일부 아동이 대상자 에 포함되었다. 예를 들어 정신지체나 심한 틱장애를 동반하여 단체활동에 방해가 되거나 중도탈락한 경우가 있었다. 둘째는 약물치료 모니터링의 부재로, 회기별 아동변화에 약물이 미칠 수 있는 영향을 배제하지 못하여 이것이 아동의 행동평가 설문 결과에 혼란요소로 작용하였을 가능성이 있다. 셋째, 심화캠 프 이후 설문평가가 이루어지지 않아 효과의 지속성을 확인하 지 못하였다. 넷째, 대상자의 수가 적어 설문지 분석이 통계적 의미를 가지기 어려운 제한점이 있었고, 대조군이 없어 치료캠프 고유의 효과검증에는 제한이 있었다. 따라서, 이 프로그램이 $\mathrm{ADHD}$ 아동과 그 부모들에 대해 나타내는 효과의 정도를 보다 객관적으로 평가하기 위해서는 위에서 언급한 제한점들을 보 완한 추가적 연구가 뒤따라야겠다.

\section{결 론}

$\mathrm{ADHD}$ 로 인해 아동과 가족이 겪는 다양한 기능영역의 문 제는 약물치료 등 단일한 치료수단만으로는 해결하기 어렵다. 본 연구에서는 아동의 행동문제와 사회기술의 문제, 부모의 양 육스트레스, 부모-자녀관계의 부조화 및 갈등에 초점을 맞추 고, 이런 점들을 해결하기 위해 통합적 접근방식을 사용하였 다. 즉, 아동을 위한 사회기술훈련, 부모를 위한 질환 및 양육 방법에 관한 교육을 숲 체험 프로그램과 유기적으로 통합하여 치료를 진행한 결과, 부모의 양육스트레스가 호전됨이 확인되
었으나, 아동의 문제행동과 정서적 어려움은 의미 있는 변화가 나타나지 않았다. 따라서, 본 연구에서 적용한 캠프 프로그램 을 통한 $\mathrm{ADHD}$ 아동의 치료효과 검증에는 한계가 있는 것으 로 보이며, 사회심리적 치료의 통합적 접근방법이 $\mathrm{ADHD}$ 에 대 한 새로운 치료모델로서 기능할 수 있기 위해서는 제한점들을 보완한 추가적 연구가 필요할 것이다.

중심 단어:주의력결핍 과잉행동장애·가족캠프 - 통합적 치 료 프로그램.

\section{References}

1) American Psychiatric Association. Diagnostic and statistical manual of mental disorders. 4th edition. Washington DC: American Psychiatric Association;1994.

2) Barkley RA. Attention-deficit hyperactivity disorder: A handbook for diagnosis and treatment. New York: Guilford Press; 1990.

3) Hinshaw SP. Attention Deficits and Hyperactivity in Children. Thousand Oaks: Sage;1994.

4) Greene RW, Biederman J, Faraone SV, Sienna M, Garcia-Jetton J. Adolescent outcome of boys with attention-deficit/hyperactivity disorder and social disability: results from a 4-year longitudinal follow-up study. J Consult Clin Psychol 1997;65:758-767.

5) Ahn DH. Attention deficit-hyperactivity disorder. J Korean Med Assoc 1995;38:1000-1007.

6) Firestone P, Kelly MJ, Goodman JT, Davey J. Differential effects of parent training and stimulant medication with hyperactives: a progress report. J Am Acad Child Psychiatry 1981;20:135-147.

7) Barkley RA, Guevremont DC, Anastopoulos AD, Fletcher KE. A comparison of three family therapy programs for treating family conflicts in adolescents with attention-deficit hyperactivity disorder. J Consult Clin Psychol 1992;60:450-462.

8) Cousins LS, Weiss G. Parent training and social skills training for children with attention-deficit hyperactivity disorder: how can they be combined for greater effectiveness? Can J Psychiatry 1993;38: 449-457.

9) Pisterman S, McGrath P, Firestone P, Goodman JT, Webster I, Mallory R. Outcome of parent-mediated treatment of preschoolers with attention deficit disorder with hyperactivity. J Consult Clin Psychol 1989;57:628-635.

10) Firestone P, Crowe D, Goodman JT, McGrath P. Vicissitudes of follow-up studies: differential effects of parent training and stimulant medication with hyperactives. Am J Orthopsychiatry 1986;56:184194.

11) Pelham WE, Hinshaw SP. Behavioral intervention for attention deficit-hyperactivity disorder. In: Tuner SM, Calhoun KS, Adams HE, editors. Handbook of Clinical Behavior Therapy. New York: Wiley \& Sons;1992. p.259-283.

12) Hong KE M, Oh KJ, Shin MS. Comparison of the treatment effects between medication only and medication-plus-parent training in ADHD children. J Korean Acad Child Adolesc Psychiatry 1995;6: 65-73.

13) Kim SS, Ahn DH, Lee YH. The effects of the combined treatment of medication and parent training in children with attention-deficit/hyperactivity disorder (ADHD). J Korean Neuropsychiatr Assoc 1998; 37:683-699.

14) Pelham WE, Hoza B. Intensive treatment: A summer treatment program for children with ADHD. In: Euthymia DH, Peter SJ, editors. Psychosocial treatments for child and adolescent disorders; Empirically based strategies for clinical practice. Washington DC: American Psychological Association;1996. p.311-340. 
15) Ahn DH, Kim SS. Oppositional child: manuals for clinicians performing assessment and parental training. Seoul: Hanaeuihaksa;1997.

16) Ahn DH, Kim SS, Han ES. Social skill training for children with attention-deficit hyperactivity disorder. Seoul: Hakjisa;2004.

17) Kovacs M. The Children's Depression, Inventory (CDI). Psychopharmacol Bull 1985;21:995-998.

18) Cho SC, Lee YS. Development of the Korean form of the Kovac's Children's Depression Inventory. J Korean Neuropsychiatr Assoc 1990;29:943-956.

19) Spielberger CD. Preliminary Professional Manual for the Test Anxiety Inventory. Palo Alto: Consulting Psychologists;1980.

20) Cho SC, Choi JS. Development of the Korean form of the State-Trait anxiety Inventory for Children. Seoul J Psychiatry 1989;14:150-157.

21) Coopersmith S. The antecedents of self-esteem. San Francisco: W.H. Freeman;1967.

22) Pope AW, McChale SM, Craighead WE. Self-esteem enhancement with children and adolescents. New York: Pergamon Press;1988.

23) Choi BG, Jeon GY. Research: a study on the development of the self-esteem inventory (1). J Korean Home Econ Assoc 1993;31:41-54.

24) Arthur LR, Sharon LF. Negotiating Parent-Adolescent conflict. New York: Guilford Press;1989.

25) Parker G, Tupling H, Brown LB. A parental bonding instrument. Br J Med Psychol 1979;52:1-10.
26) Song JY. The development of the Parental Bonding Instrument-Korean version : evaluation of the test reliability and validity. J Korean Neuropsychiatr Assoc 1992;31:979-992.

27) Achenbach TM, Edelbrock C. Manual for the Child Behavior Checklist and Revised Child Behavior Profile. Burlington: University of Vermont;1983.

28) Oh KJ, Lee H, Hong KE, Ha EH. Korean version of Child Behavior Checklist (K-CBCL). Seoul: ChungAng Aptitude Publishing;1997.

29) Barkley RA. Defiant children: Parent-teacher assignments. New York: Guilford Press;1987.

30) Kim MK, Ahn DH, Lee YH. Analyses of characteristics in children with attention-deficit hyperactivity disorder and learning problem. Ment Health Res 1996;15:122-133.

31) Gresham FM, Elliott SN. Social Skills Rating System Manual. Circle Pines, MN: American Guidance Service; 1990.

32) Han ES, Ahn DH, Lee YH. The social skills training in children with attention-deficit hyperactivity disorder (ADHD). J Korean Acad Child Adolesc Psychiatry 2001;12:79-93.

33) Abidin RR. Parenting Stress Index. Charlottesville, VA: Pediatric Psychology Press;1990.

34) Kim TR, Park RG, Lee KS. Parental perceptions of child adjustment associated with parenting stress with autistic children. J Kor Acad Child Adolesc Psychiatry 1992;3:106-116. 